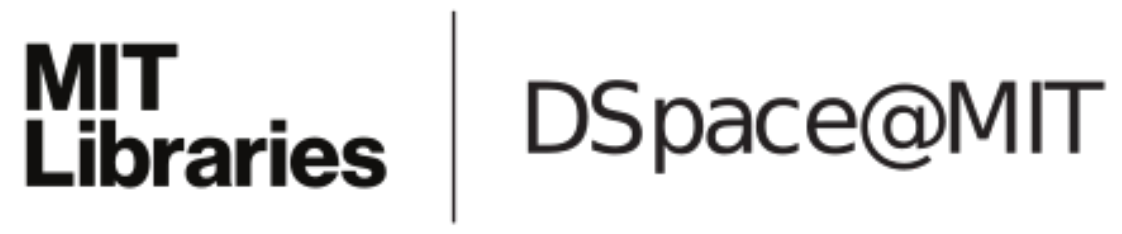

\author{
MIT Open Access Articles
}

Infective endocarditis and cancer in the elderly

The MIT Faculty has made this article openly available. Please share how this access benefits you. Your story matters.

Citation: García-Albéniz, Xabier, John Hsu, Marc Lipsitch, Roger W. Logan, Sonia HernándezDíaz, and Miguel A. Hernán. "Infective Endocarditis and Cancer in the Elderly." European Journal of Epidemiology 31, no. 1 (December 18, 2015): 41-49.

As Published: http://dx.doi.org/10.1007/s10654-015-0111-9

Publisher: Springer Netherlands

Persistent URL: http://hdl.handle.net/1721.1/105842

Version: Author's final manuscript: final author's manuscript post peer review, without publisher's formatting or copy editing

Terms of Use: Article is made available in accordance with the publisher's policy and may be subject to US copyright law. Please refer to the publisher's site for terms of use. 


\title{
Infective endocarditis and cancer in the elderly
}

\author{
Xabier García-Albéniz ${ }^{1,2} \cdot$ John Hsu ${ }^{2,3} \cdot$ Marc Lipsitch $^{1,4} \cdot \operatorname{Roger}$ W. Logan ${ }^{1} \cdot$ \\ Sonia Hernández-Díaz ${ }^{1}$ Miguel A. Hernán ${ }^{1,5,6}$
}

Received: 10 September 2015/ Accepted: 10 December 2015/Published online: 18 December 2015

(C) Springer Science+Business Media Dordrecht 2015

\begin{abstract}
Little is known about the magnitude of the association between infective endocarditis and cancer, and about the natural history of cancer patients with concomitant diagnosis of infective endocarditis. We used the SEER-Medicare linked database to identify individuals aged 65 years or more diagnosed with colorectal, lung, breast, or prostate cancer, and without any cancer diagnosis ( $5 \%$ random Medicare sample from SEER areas) between 1992 and 2009. We identified infective endocarditis from the ICD-9 diagnosis of each admission recorded in the Medpar file and its incidence rate 90 days around cancer diagnosis. We also estimated the overall survival and CRCspecific survival after a concomitant diagnosis of infective endocarditis. The peri-diagnostic incidence of infective endocarditis was 19.8 cases per 100,000 person-months for CRC, 5.7 cases per 100,000 person-months for lung cancer,
\end{abstract}

Electronic supplementary material The online version of this article (doi:10.1007/s10654-015-0111-9) contains supplementary material, which is available to authorized users.

Xabier García-Albéniz

xabi@post.harvard.edu

1 Department of Epidemiology, Harvard T.H. Chan School of Public Health, 677 Huntington Ave, Boston, MA 02115, USA

2 Mongan Institute for Health Policy, Massachusetts General Hospital, Boston, MA, USA

3 Department of Health Care Policy, Harvard Medical School, Boston, MA, USA

4 Department of Immunology and Infectious Diseases, Harvard T.H. Chan School of Public Health, Boston, MA, USA

5 Department of Biostatistics, Harvard T.H. Chan School of Public Health, Boston, MA, USA

6 Harvard-MIT Division of Health Sciences and Technology, Boston, MA, USA
1.9 cases per 100,000 person-months for breast cancer, 4.1 cases per 100,000 person-months for prostate cancer and 2.4 cases per 100,000 person-months for individuals without cancer. Two-year overall survival was $46.4 \%$ (95\% CI 39.5, 54.5\%) for stage I-III CRC patients with concomitant endocarditis and $73.1 \%$ (95\% CI 72.9 , $73.3 \%$ ) for those without it. In this elderly population, the incidence of infective endocarditis around CRC diagnosis was substantially higher than around the diagnosis of lung, breast and prostate cancers. A concomitant diagnosis of infective endocarditis in patients with CRC diagnosis is associated with shorter survival.

Keywords Infective endocarditis - Colorectal cancer . SEER · Medicare

\section{Introduction}

Colorectal, lung, breast, and prostate cancer account for about half of cancers in the United States and in Europe, with more than 800,000 and 1,370,000 new diagnoses per year respectively [1,2]. The care of these patients is complex and invasive, particularly during the initial year after diagnosis. Concurrent infections may interfere with patient care and lead to worse outcomes. In particular, among patients with colorectal cancer (CRC), Streptococcus gallolyticus (formerly named Streptococcus bovis biotype I) appears to be associated with an increased risk of infective endocarditis [3].

The association between CRC and endocarditis was first proposed decades ago [4], and is supported by several case series [5] and small case-control studies [6-8]. A metaanalysis of these case-control studies found a strong association (odds ratio 14.5, $95 \%$ confidence interval 
5.7-37.6), but it was based on only 16 CRC patients with endocarditis [9] and could not provide information about the incidence of endocarditis around CRC diagnosis. Further, few data exist about the association between endocarditis and the outcomes of CRC patients [10], or between endocarditis and other tumor sites [11].

Here we present the first large-scale prospective study of peridiagnostic incidence of endocarditis among patients with colorectal, breast, lung, and prostate cancer. We also evaluate the association between peridiagnostic endocarditis and the prognosis of patients with CRC.

\section{Methods}

\section{Study population}

Our study population was extracted from the SEERMedicare data, a linkage of patient demographic and tumor-specific variables collected by 17 SEER cancer registries across 12 states of the United States with Medicare claim files from the Centers for Medicare and Medicaid Services [12]. SEER data are summarized in the Patient Entitlement and Diagnosis Summary File (PEDSF), which is linked with $100 \%$ of Medicare claims. For the current study we used Medicare claims from the Inpatient, Outpatient, Home Health Agency (HHA), Durable Medical Equipment (DME), Medpar and National Claims History $(\mathrm{NCH})$ files. To identify the date of cancer diagnosis we used the SEER date of diagnosis, which is the month, and year the tumor was first diagnosed, clinically or microscopically, by a recognized medical practitioner [13].

We included patients with histological diagnosis of invasive colorectal adenocarcinoma, lung cancer, breast cancer, or prostate cancer between 1992 and 2009, and who were enrolled in Medicare parts A and B and not in an health maintenance organization during the year before diagnosis. As a control group, we included patients without cancer using a random $5 \%$ sample of Medicare beneficiaries living in areas with SEER registries. We excluded patients with cancers reported by nursing home/ hospice, autopsy, or death certificate, and those with an endocarditis diagnosis 12 or more months before cancer diagnosis.

We identified endocarditis from the principal or secondary ICD-9 diagnosis (see codes in table A1) of each admission recorded in the Medpar file [14]. From the PEDSF file, we determined demographic characteristics (age, sex, race, urbanicity), tumor features (TNM stage, grade of differentiation, SEER date of diagnosis) and census tract features (census region, percentage of black population, percentage of residents living below the poverty level, percentage of residents aged 25 or older with less than 12 years of education, percentage of residents speaking English not well/not at all at age $65+$, median income). We summarized comorbidity burden using the Deyo-Charlson-Klabunde comorbidity index [15], derived from the inpatient and outpatient Medicare claims for the period between 12 months to the month before SEER date of diagnosis. We extracted cancer-directed diagnostic tests and therapy (colonoscopy, colectomy, chemotherapy) from the NCH, Outsaf, Medpar and DME files (see codes in table A1) and admissions in the year following cancer diagnosis from the Medpar file. We also extracted the colorectal cancer sentinel sign/symptom (anemia, gastrointestinal bleeding, gastrointestinal symptoms, large bowel obstruction, see codes in table A1) from claims issued during the 3 months previous SEER date of diagnosis. As falsification tests (negative controls for endocarditis), we examined the risk of two other serious infections that are unlikely to be related to either CRC or $\mathrm{CRC}$ care, i.e., pyelonephritis and meningitis.

\section{Data analysis}

We followed patients from 1 year before cancer diagnosis (random reference date for the non-cancer cohort) until they died, stopped fulfilling the inclusion criteria, or reached the administrative end of follow-up (December 31st, 2010). In our main analyses, we computed the peridiagnostic incidence rate of endocarditis between 90 days before and 90 after cancer diagnosis: number of endocarditis diagnoses divided by number of person-months in that time period. For lung, breast and prostate cancer, we standardized the rate by the age $(\leq 70,71-75,76-85,>85)$ and sex (for lung cancer only) distribution of CRC patients. We also plotted the monthly incidence rate of endocarditis from -12 to +24 months from cancer diagnosis.

We defined overall survival and cancer-related survival as the time from SEER date of diagnosis to death by any cause or cancer respectively. We classified patients as having a concomitant diagnosis of endocarditis if they were diagnosed with endocarditis between 90 days before and 90 days after cancer diagnosis, and as having no concomitant diagnosis of endocarditis otherwise. We constructed Kaplan-Meier curves for survival and cancerrelated survival by concomitant endocarditis, and estimated the hazard ratios for endocarditis versus no endocarditis using a Cox model adjusted by sex, age, stage, comorbidity score, structural cardiac condition and presence of an intravascular device. We used a non-parametric bootstrap based on 1000 resamplings to compute $95 \%$ confidence intervals for survival differences at 24 months of followup. We used SAS version 9.4 (SAS Institute, Cary, NC) and $\mathrm{R}[16]$. 


\section{Results}

There were 1835 new cases of endocarditis among cancer patients (Fig. 1). For CRC patients, the peri-diagnostic endocarditis incidence rate was 19.8 cases per 100,000 person-months (95\% CI 17.0-22.6). The corresponding rates were much lower for lung, breast, and prostate cancer, and for individuals without cancer (Table 1). In contrast, the incidence of peri-diagnostic pyelonephritis and meningitis did not substantially differ by cancer site and were higher than in patients without cancer (Supplementary Table A2). The endocarditis rate was highest during the month of diagnosis for both CRC (42.1 cases per 100,000 person-months, $95 \%$ CI 32.3, 52.0) and lung cancer (15.6 cases per 100,000 person-months, $95 \%$ CI 10.2, 21.0), but not for breast and prostate cancer (Fig. 2). The use of colonoscopy increases after admission due to an endocarditis (Supplementary Figure A1).

CRC patients with a concomitant diagnosis of endocarditis were more likely to be male, have a structural cardiac condition or intravascular device, have a higher comorbidity score, have presented with anemia as a sentinel symptom, and been diagnosed at earlier stages (Table 2). Among patients diagnosed with potentially curable CRC (stages I to III), the concomitant diagnosis of endocarditis was associated with a higher postoperative mortality, smaller percentage of patients receiving adjuvant therapy, higher percentage of patients visiting the emergency department, longer lengths of admissions, longer stays in intensive care units, and more clinical evaluations during the first year after CRC diagnosis, compared with not having endocarditis (Table 3).

Two-year overall survival (95\% CI) was $46.4 \%$ (39.5, 54.5) for stage I-III CRC patients with a concomitant diagnosis of endocarditis and $73.1 \%(72.9,73.3)$ for those without it (risk difference $-26.7 \%$; $95 \%$ CI -33.8 , -19.0). These differences were present across the three stages (Table 3; Fig. 3). In contrast, the two-year cancerspecific survival was $84.9 \%(79.0,91.2)$ for those with a concomitant diagnosis of endocarditis and $85.7 \%$ (85.5, 85.9) for those without it (risk difference $-0.7 \%$; $95 \% \mathrm{CI}$ $-6.8,5.3)$. There were no relevant differences by stage (Table 3; Fig. 3). Compared with no concomitant diagnosis of endocarditis, the hazard ratio for an endocarditis diagnosis was 1.67 (95\% CI 1.42, 1.98) for overall mortality and $1.24(95 \% \mathrm{CI} 0.87,1.77)$ for cancer-specific mortality during a median follow-up of 34 months (interquartile range, 12-72 months).
Patients diagnosed with cancer in the years 1992-2009 $\mathrm{N}=1,690,873$

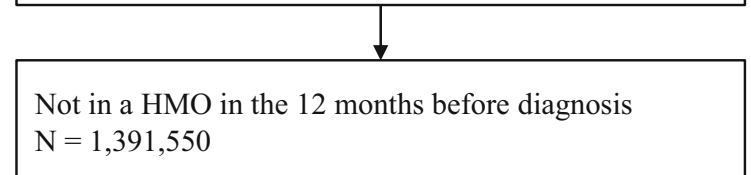

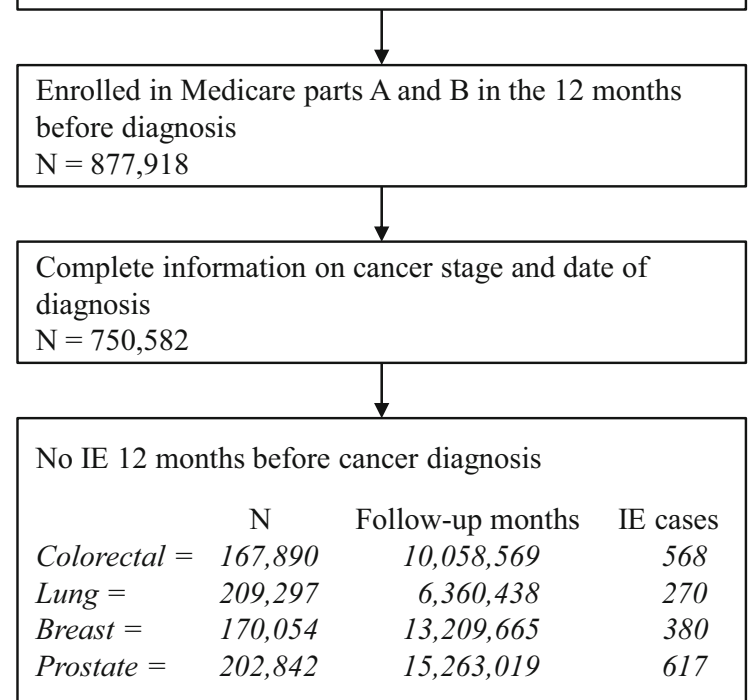

Patients without cancer, with a reference date within the years 1992-2009

$\mathrm{N}=740,983$

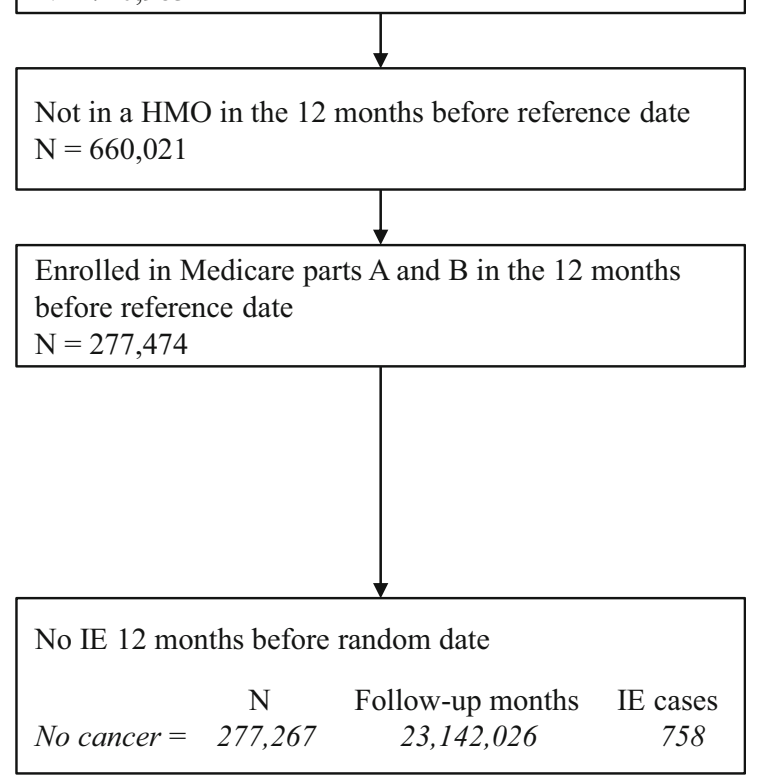

Fig. 1 Flowchart of individuals' selection into the study (HMO health maintenance organization, $I E$ infective endocarditis), SEER-Medicare 1992-2009 
Table 1 Incidence rate of infective endocarditis between 90 days before and 90 days after diagnosis of colorectal, lung, breast, and prostate cancer, SEER-Medicare 1992-2009

\begin{tabular}{lccccc}
\hline Cancer site & Persons & Person-months & Cases & \multicolumn{2}{l}{ Cases per 100,000 person-months (95 \% CI) } \\
\cline { 5 - 6 } & & & & Unadjusted rate & Standardized rate $^{\mathrm{a}}$ \\
\hline Colorectal & 167,851 & 966,072 & 191 & $19.8(17.0-22.6)$ & $19.8(17.0-22.6)$ \\
Lung & 209,258 & $1,163,085$ & 70 & $6.0(4.6-7.4)$ & $5.7(4.2-7.1)$ \\
Breast & 170,041 & $1,000,659$ & 17 & $1.7(0.9-2.5)$ & $1.9(1.0-2.8)$ \\
Prostate & 202,820 & $1,195,057$ & 44 & $3.7(2.6-4.8)$ & $4.1(2.8-5.4)$ \\
Non-cancer & 277,207 & $1,631,021$ & 37 & $2.3(1.5-3.0)$ & $2.4(1.5-3.2)$ \\
\hline
\end{tabular}

${ }^{a}$ Incidence rate is directly standardized to the age and sex (except for breast and prostate cancer) distribution of CRC patients

b Incidence rate is calculated using a random index date
Fig. 2 Monthly rates of infective endocarditis around diagnosis of colorectal (CRC), lung, breast and prostate cancer (PROST), and around a random date for individuals without cancer, SEER-Medicare 1992-2009
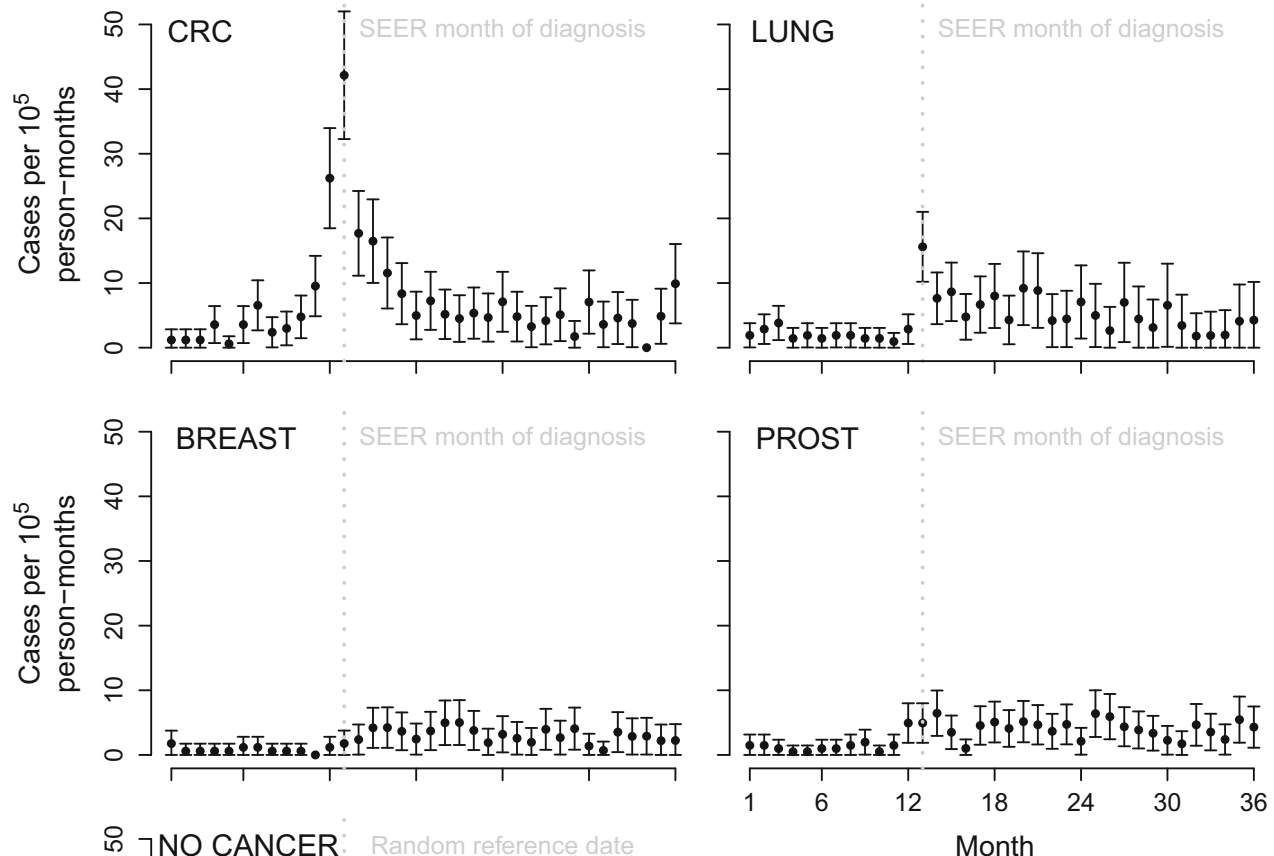

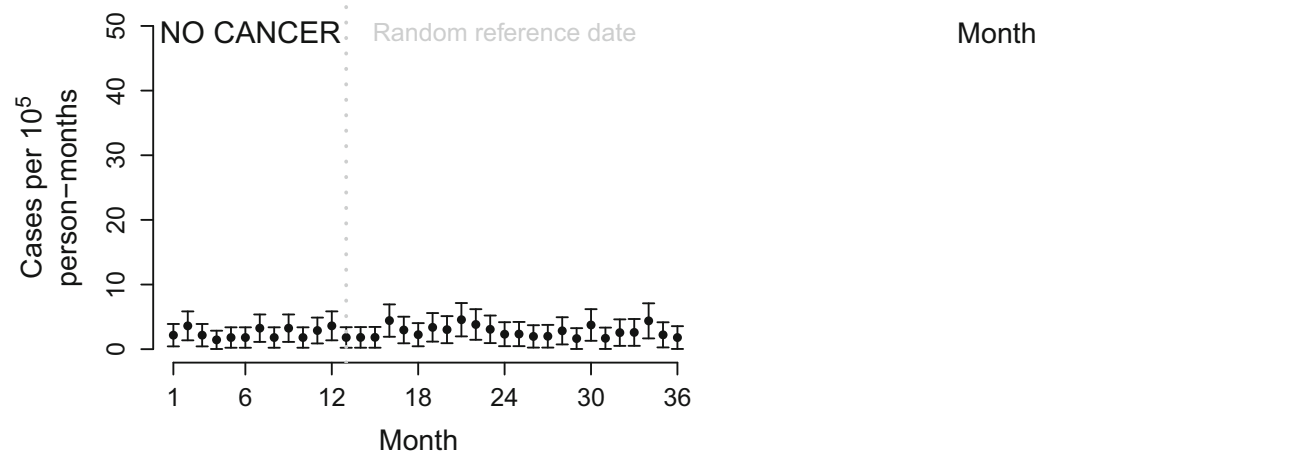

\section{Discussion}

We found that the incidence of endocarditis in the elderly increased fivefold around the diagnosis of CRC compared with the diagnosis of lung, breast, or prostate cancer, or an arbitrary date for individuals without cancer. An increased incidence was not observed for other serious infections.
Our study included over five times more CRC patients with endocarditis than all previous studies combined, and provided the first estimate of endocarditis incidence surrounding the diagnosis of CRC in the elderly: 19.8 cases (95\% CI 17.0-22.6) per 100,000 person-months.

The association between endocarditis and CRC diagnosis can be due to at least four non-mutually exclusive 
Table 2 Characteristics of colorectal cancer patients with and without a concomitant diagnosis of infective endocarditis, SEER-Medicare 1992-2009

\begin{tabular}{|c|c|c|}
\hline & No endocarditis $(\mathrm{N}=167,699)$ & Endocarditis $(\mathrm{N}=191)$ \\
\hline Median age (interquartile range) & $77(71-83)$ & $78(72-83)$ \\
\hline Female $(\%)$ & 53.3 & 38.2 \\
\hline \multicolumn{3}{|l|}{ Race $(\%)$} \\
\hline White & 86.5 & 89.5 \\
\hline African American & 8.9 & $*$ \\
\hline Asian/Pacific islander & 4.2 & $*$ \\
\hline Other/unknown/unspecified & 0.5 & $*$ \\
\hline \multicolumn{3}{|l|}{ Comorbidity score $^{\mathrm{a}}(\%)$} \\
\hline 0 & 52.7 & 39.3 \\
\hline 1 & 21.3 & $>17.2$ \\
\hline $2+$ & 14.9 & 37.7 \\
\hline Unknown & 11.0 & $<5.8$ \\
\hline Structural cardiac condition $^{\mathrm{a}}(\%)$ & 10.6 & 34.6 \\
\hline Intravascular device $^{\mathrm{a}}(\%)$ & 3.0 & 10.5 \\
\hline End stage renal disease ${ }^{\mathrm{a}}(\%)$ & 0.8 & $*$ \\
\hline \multicolumn{3}{|l|}{ Sentinel symptom ${ }^{\mathrm{b}}(\%)$} \\
\hline Anemia & 26.4 & 42.9 \\
\hline Gastrointestinal bleeding & 24.1 & 29.3 \\
\hline Gastrointestinal symptoms & 17.7 & 19.9 \\
\hline Large bowel obstruction & 2.4 & $*$ \\
\hline \multicolumn{3}{|l|}{ Stage $(\%)$} \\
\hline I & 26.8 & 38.2 \\
\hline II & 31.5 & 32.5 \\
\hline III & 25.0 & 19.9 \\
\hline IV & 16.8 & 9.4 \\
\hline \multicolumn{3}{|l|}{ Grade of differentiation (\%) } \\
\hline Well differentiated & 8.9 & 13.6 \\
\hline Moderately differentiated & 63.9 & 62.3 \\
\hline Poorly differentiated & 19.2 & 17.8 \\
\hline Unknown & 8.0 & 6.3 \\
\hline \multicolumn{3}{|l|}{ Location (\%) } \\
\hline Ascending colon & 35.3 & 31.4 \\
\hline Transverse colon & 14.5 & 16.7 \\
\hline Descending colon & 27.1 & 26.7 \\
\hline Rectum & 23.1 & 25.1 \\
\hline \multicolumn{3}{|l|}{ Urbanicity (\%) } \\
\hline Big metro ( $\geq 1$ million) & 54.0 & 58.6 \\
\hline Metro (250,000-1 million) & 28.4 & 29.3 \\
\hline Urban $(20,000-250,000)$ & 6.2 & $*$ \\
\hline Less urban $(2500-20,000)$ & 9.3 & $*$ \\
\hline Rural (rural or <2500) & 2.2 & $*$ \\
\hline \multicolumn{3}{|l|}{ SEER registry census region $(\%)$} \\
\hline West & 38.2 & 37.2 \\
\hline Northeast & 20.5 & 34.0 \\
\hline Midwest & 19.0 & 12.0 \\
\hline South & 20.7 & 16.2 \\
\hline Pacific & 1.6 & $*$ \\
\hline
\end{tabular}


Table 2 continued

\begin{tabular}{lll}
\hline & No endocarditis $(\mathrm{N}=167,699)$ & Endocarditis $(\mathrm{N}=191)$ \\
\hline Year of CRC diagnosis (\%) & & 18.9 \\
1992-1996 & 19.0 & 20.4 \\
$1997-2001$ & 26.1 & 30.9 \\
$2002-2006$ & 30.4 & 29.8 \\
$2007-2010$ & 24.5 & $15.5(8.9-24.3)$ \\
Census tract features [median (interquartile range)] & & $7.0(4.0-11.6)$ \\
\% did not complete high school & $16.7(10.0-27.1)$ & $2.1(0.7-6.7)$ \\
\% below poverty line & $8.4(4.5-15.6)$ & $2.1(0-5.9)$ \\
\% black race/ethnicity & $2.1(0.6-8.3)$ & $49,131(35,334-62,316)$ \\
English not well/at all at 65+ & $1.5(0-5.4)$ & $42,219(31,906-57,068)$ \\
\hline
\end{tabular}

* Cells with counts of 11 or lower $(\leq 5.8 \%)$ are blinded following SEER-Medicare privacy policy

${ }^{\text {a }}$ Evaluated the 6th month before colorectal cancer diagnosis

b Evaluated during the 3 months preceding colorectal cancer diagnosis

${ }^{c}$ Missing in 1296 individuals

Table 3 Oncologic management and outcomes in patients diagnosed with stages I-III of colorectal cancer by concomitant diagnosis of infective endocarditis, SEER-Medicare 1992-2009

\begin{tabular}{|c|c|c|}
\hline & $\begin{array}{l}\text { No endocarditis } \\
(\mathrm{N}=139,600)\end{array}$ & $\begin{array}{l}\text { Endocarditis } \\
(\mathrm{N}=173)\end{array}$ \\
\hline Surgery of primary tumor $(\%)$ & 79.5 & 84.4 \\
\hline Postoperative mortality $^{\mathrm{a}}(\%)$ & 6.0 & 12.0 \\
\hline Adjuvant chemotherapy ${ }^{\mathrm{b}}(\%)$ & 14.5 & $\mathrm{~d}$ \\
\hline Patients visiting the emergency department during 1st year after CRC diagnosis (\%) & 50.2 & 79.2 \\
\hline Median (interquartile range) number of visits & $2(1-3)$ & $2(1-4)$ \\
\hline Patients admitted to a hospital during 1 st year after CRC diagnosis $(\%)$ & 90.3 & 95.4 \\
\hline Median length of total stay ${ }^{\mathrm{c}}$ (interquartile range) & $13(7-27)$ & $43(25-73)$ \\
\hline Median number of days in intensive care ${ }^{\mathrm{d}}$ (interquartile range) & $0(0-3)$ & $4(0-10)$ \\
\hline $\begin{array}{l}\text { Median number of clinical evaluations during 1st year after CRC diagnosis (interquartile } \\
\text { range) }\end{array}$ & $22(12-36)$ & $43(26-66)$ \\
\hline Number of deaths & 89,172 & 139 \\
\hline Number of cancer-related deaths & 32,945 & 31 \\
\hline Months of follow-up & $9,315,640$ & 8,187 \\
\hline \multicolumn{3}{|l|}{ 2-year overall survival (\%) } \\
\hline Stage I & $80.6(80.2-80.9)$ & $50.6(38.7-61.4)$ \\
\hline Stage II & $74.1(73.7-74.5)$ & $41.4(29.0-53.4)$ \\
\hline Stage III & $63.8(63.4-64.3)$ & $46.9(30.5-61.8)$ \\
\hline \multicolumn{3}{|l|}{ 2-year CRC-specific survival (\%) } \\
\hline Stage I & $93.4(93.2-93.7)$ & $90.0(79.0-95.0)$ \\
\hline Stage II & $87.1(86.8-87.4)$ & $80.9(66.0-89.8)$ \\
\hline Stage III & $75.5(75.1-75.9)$ & $80.1(60.0-90.8)$ \\
\hline
\end{tabular}

${ }^{\text {a }}$ Postoperative mortality defined as death in the 30 days following surgery

b Stages II and III $(\mathrm{N}=94,840)$

c Sum of days that year through all admissions

${ }^{\mathrm{d}}$ Cells with counts of 11 or lower $(\leq 6.4 \%)$ are blinded following SEER-Medicare privacy policy 
Fig. 3 Overall survival (OS) and colorectal cancer-specific survival (CRC-SS) stratified by infective endocarditis, and by infective endocarditis and stage, SEER-Medicare 1992-2009
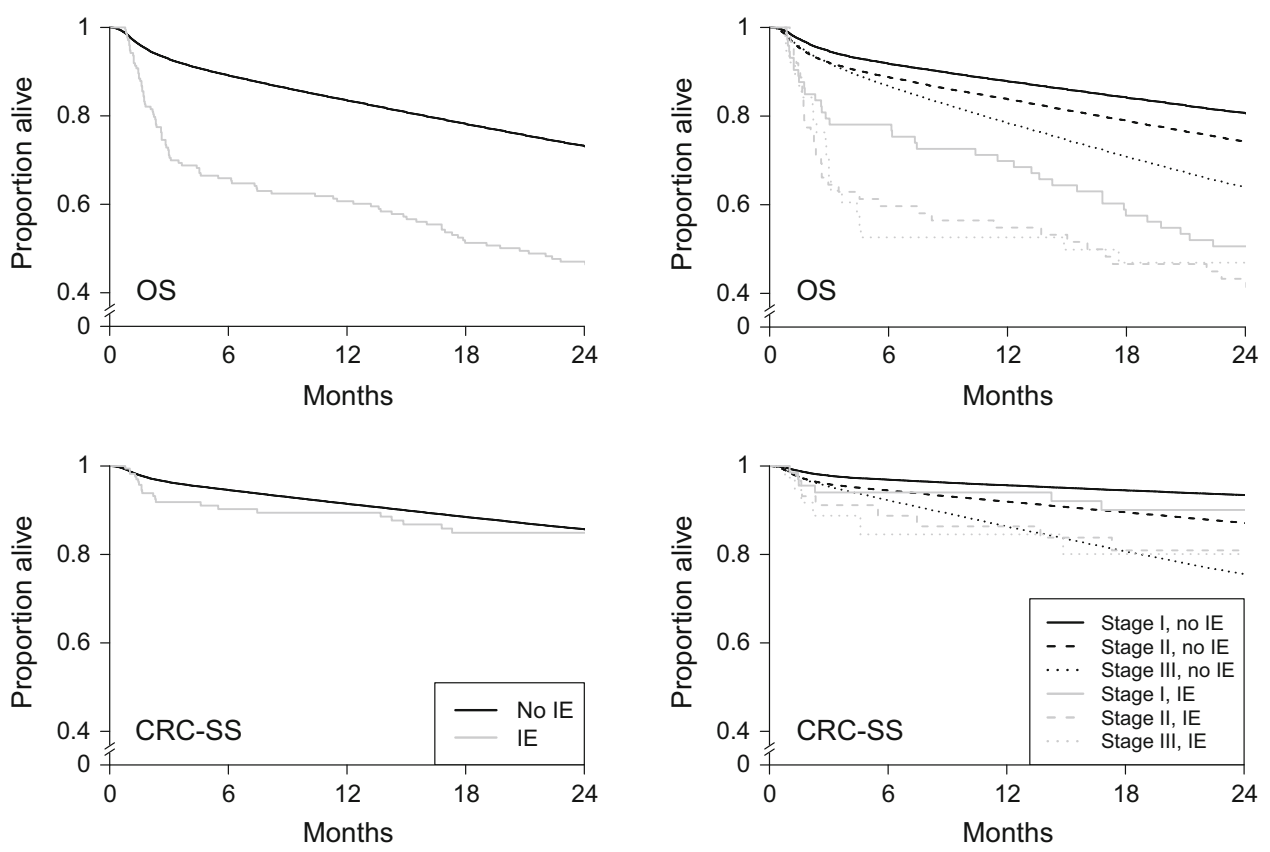

No. at risk

$\begin{array}{ll}\text { No IE139600 } & 115415 \\ \text { IE } 173 & 105\end{array}$

No. at risk

$\begin{array}{lll}95194 & \text { S. I, no IE } & 44860 \\ 73 & \text { S. II, no IE } & 52766 \\ & \text { S. III, no IE } 41974 \\ & \text { S. I, IE } & 73 \\ \text { S. II, IE } & 62 \\ \text { S. III, IE } & 38\end{array}$

$\begin{array}{ll}38974 & 33566 \\ 43802 & 36550 \\ 32639 & 25078 \\ 51 & 35 \\ 34 & 23 \\ 20 & 15\end{array}$

reasons, which are summarized in Fig. 4. First, undiagnosed CRC (or pre-neoplastic lesions like adenomas) could cause endocarditis, perhaps by allowing the translocation of bacteria [17] (Fig. 4a). Second, patients diagnosed with endocarditis often receive a subsequent colonoscopy as part of the diagnostic work-up (Supplementary Figure A1), which could lead to a higher rate of CRC detection (Fig. 4b). Third, a common causative factor could independently lead to CRC diagnosis and endocarditis (Fig. 4c). For example, colonoscopy could cause both an increased rate of CRC diagnosis and of endocarditis by disrupting the bowel mucosal barrier and thus facilitate the seeding of bacteria in the bloodstream. The colonoscopy can be performed for screening purposes as shown in Fig. $4 \mathrm{c}$ or as a result of CRC symptoms (i.e. Figure $4 \mathrm{c}$ with an arrow from CRC to colonoscopy). Similarly, the observed small increase in endocarditis incidence in the month of lung cancer diagnosis supports the hypothesis that localized trauma associated with diagnostic procedures (in this case bronchoscopy) might increase the risk of endocarditis. Finally, the association between CRC and endocarditis could be due to common etiologic factors such as immunosuppression, smoking, and alcohol (Fig. 4d).

Regardless of the reason why endocarditis and CRC diagnosis are associated, CRC patients with concomitant endocarditis had a $25 \%$ increase in two-year mortality, but no changes in CRC-specific mortality. This increased mortality risk suggests that clinicians need to be vigilant for endocarditis in CRC patients, particularly during the peri-diagnostic period. Future studies on the risks and benefits of anti-microbial prophylaxis also could be warranted. Not only did endocarditis increase the risk of noncancer specific death, but it also was associated with changes in cancer treatment. Because decisions on oncologic therapies depend on the predicted survival of patients, our findings will help inform clinical decisions in elderly patients, an increasing fraction of the oncologic patients $[18,19]$ who are under-represented in clinical research [20]. Our results suggest that the increase in mortality associated to endocarditis is not through worse oncological outcomes.

Our study has several limitations. While the quality of the diagnosis of cancer in SEER-Medicare is high, no formal validation of endocarditis diagnoses in Medicare claims has been done. However, endocarditis represents a serious infection for which patients are unlikely to avoid care, and an expensive condition for which care is likely to be well documented in claims data. Further, ICD-9 codes have been found to be accurate surrogates of bacterial infections in other administrative datasets [21] and have 
(A)

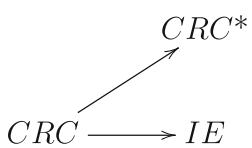

(B)

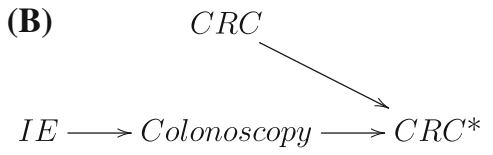

(C)

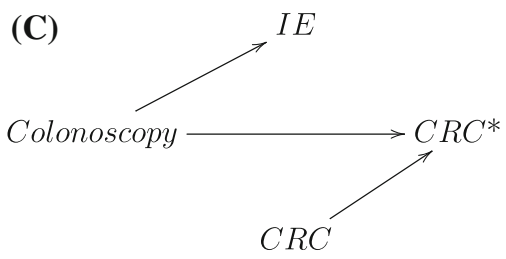

(D)

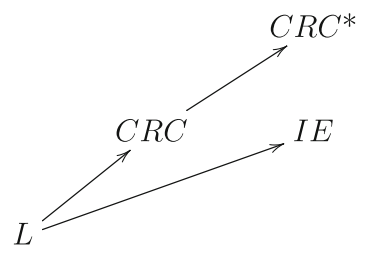

Fig. 4 Causal diagrams [27] for several explanations for the association between colorectal cancer diagnosis and infective endocarditis (CRC presence of colorectal cancer or precursor lesions, $C R C^{*}$ diagnosis of colorectal cancer, $I E$ infective endocarditis, $L$ common causes of CRC and IE)

been used as the basis of several studies on endocarditis $[14,22,23]$. Classifying patients as having a concomitant diagnosis of endocarditis if they were diagnosed with endocarditis between 90 days before and 90 days after cancer diagnosis might introduce a selection bias because patients that do not survive for at least 90 days after the date of cancer diagnosis are less likely to be classified in the endocarditis group. However, only $7 \%$ patients died during this period and sensitivity analyses using 60 or 120 days instead of 90 days yielded equivalent results (Supplementary Table A3). Our large database study lacked bacteriological data, but the pathogen most frequently associated with endocarditis among CRC patients is Streptococcus gallolyticus subsp. gallolyticus (formerly Streptococcus bovis I) [3], possibly because of its ability to translocate through the bowel wall when its permeability is increased by cancer [24], its immune-evasion properties [25], and its affinity to the collagen type I in damaged heart valves [26].

In summary, our study provides a precise estimate of the association between CRC and endocarditis as well as of the association between endocarditis and the survival of older adults with CRC. These findings help inform clinical decisions for cancer patients, including the diagnostic workup of patients with CRC and fever of unknown origin, as well as cost-effectiveness assessments of clinical pathways for CRC care.

Acknowledgments The authors acknowledge the efforts of the Applied Research Program, NCI; the Office of Research, Development and Information, CMS; Information Management Services (IMS), Inc.; and the Surveillance, Epidemiology, and End Results (SEER) Program tumor registries in the creation of the SEERMedicare database. The interpretation and reporting of these data are the sole responsibility of the authors. The collection of the California cancer incidence data used in this study was supported by the California Department of Public Health as part of the statewide cancer reporting program mandated by California Health and Safety Code Section 103885; the National Cancer Institute's Surveillance, Epidemiology and End Results Program under contract N01-PC-35136 awarded to the Northern California Cancer Center, contract N01-PC35139 awarded to the University of Southern California, and contract N02-PC-15105 awarded to the Public Health Institute; and the Centers for Disease Control and Prevention's National Program of Cancer Registries, under agreement \#U55/CCR921930-02 awarded to the Public Health Institute. The ideas and opinions expressed herein are those of the author(s) and endorsement by the State of California, Department of Public Health the National Cancer Institute, and the Centers for Disease Control and Prevention or their Contractors and Subcontractors is not intended nor should be inferred. This work was partly funded by NIH Grants P01-CA134294, R01CA164023, R01HS023128. XGA is a recipient of a Grant from the Raymond P. Lavietes Foundation.

\section{Compliance with ethical standards}

Conflict of interest The authors declare that they have no conflict of interest.

\section{References}

1. Siegel R, Desantis C, Jemal A. Colorectal cancer statistics, 2014. CA Cancer J Clin. 2014;64:104-17.

2. Ferlay J, Steliarova-Foucher E, Lortet-Tieulent J, Rosso S, Coebergh JWW, Comber H, et al. Cancer incidence and mortality patterns in Europe: estimates for 40 countries in 2012. Eur $\mathbf{J}$ Cancer. 2013;49:1374-403.

3. Boleij A, Tjalsma H. The itinerary of Streptococcus gallolyticus infection in patients with colonic malignant disease. Lancet Infect Dis. 2013;13:719-24.

4. McCoy WC, Mason JM. Enterococcal endocarditis associated with carcinoma of the sigmoid; report of a case. J Med Assoc State Ala. 1951;21:162-6.

5. Boleij A, van Gelder MMHJ, Swinkels DW, Tjalsma H. Clinical importance of Streptococcus gallolyticus infection among colorectal cancer patients: systematic review and meta-analysis. Clin Infect Dis. 2011;53:870-8.

6. Sharara AI, Abou Hamdan T, Malli A, El-Halabi MM, Hashash JG, Ghaith OA, et al. Association of Streptococcus bovis endocarditis and advanced colorectal neoplasia: a case-control study. J Dig Dis. 2013;14:382-7.

7. Hoen B, Briançon S, Delahaye F, Terhé V, Etienne J, Bigard MA, et al. Tumors of the colon increase the risk of developing Streptococcus bovis endocarditis: case-control study. Clin Infect Dis. 1994;19:361-2. 
8. Corredoira-Sánchez J, García-Garrote F, Rabuñal R, LópezRoses L, García-País MJ, Castro E, et al. Association between bacteremia due to Streptococcus gallolyticus subsp. gallolyticus (Streptococcus bovis I) and colorectal neoplasia: a case-control study. Clin Infect Dis. 2012;55:491-6.

9. Krishnan S, Eslick GD. Streptococcus bovis infection and colorectal neoplasia: a meta-analysis. Colorectal Dis. 2014;16: 672-80.

10. Ouaïssi M, Studer A-S, Mege D, Thuny F, Boiron L, Loundou A, et al. Characteristics and natural history of patients with colorectal cancer complicated by infectious endocarditis. Case control study of 25 patients. Anticancer Res. 2014;34:349-53.

11. Gold JS, Bayar S, Salem RR. Association of Streptococcus bovis bacteremia with colonic neoplasia and extracolonic malignancy. Arch Surg. 2004;139:760-5.

12. Warren JL, Klabunde CN, Schrag D, Bach PB, Riley GF. Overview of the SEER-Medicare data: content, research applications, and generalizability to the United States elderly population. Med Care. 2002;40:IV-3--18.

13. Adamo M, Johnson C, Ruhl J, Dickie L, editors. 2011 SEER program coding and staging manual. Bethesda, MD: National Cancer Institute, NIH Publication number 11-5581. http://seer.cancer.gov/ archive/manuals/2011/SPCSM_2011_maindoc_09272011.pdf.

14. Bikdeli B, Wang Y, Kim N, Desai MM, Quagliarello V, Krumholz HM. Trends in hospitalization rates and outcomes of endocarditis among Medicare beneficiaries. J Am Coll Cardiol. 2013;62:2217-26.

15. Klabunde CN, Potosky AL, Legler JM, Warren JL. Development of a comorbidity index using physician claims data. J Clin Epidemiol. 2000;53:1258-67.

16. $\mathrm{R}$ Core Team. R: A language and environment for statistical computing. Vienna, Austria; 2014. http://www.r-project.org/.

17. Soler AP, Miller RD, Laughlin KV, Carp NZ, Klurfeld DM, Mullin JM. Increased tight junctional permeability is associated with the development of colon cancer. Carcinogenesis. 1999;20:1425-31.
18. Smith BD, Smith GL, Hurria A, Hortobagyi GN, Buchholz TA. Future of cancer incidence in the United States: burdens upon an aging, changing nation. J Clin Oncol. 2009;27:2758-65.

19. Klapper S. Focus on geriatric oncology: ASCO prepares for an aging nation. ASCO Connect. 2015;6:12-20.

20. Scher KS, Hurria A. Under-representation of older adults in cancer registration trials: known problem, little progress. J Clin Oncol. 2012;30:2036-8.

21. Schneeweiss S, Robicsek A, Scranton R, Zuckerman D, Solomon DH. Veteran's affairs hospital discharge databases coded serious bacterial infections accurately. J Clin Epidemiol. 2007;60: 397-409.

22. Prutkin JM, Reynolds MR, Bao H, Curtis JP, Al-Khatib SM, Aggarwal S, et al. Rates of and factors associated with infection in 200909 Medicare implantable cardioverter-defibrillator implants: results from the national cardiovascular data registry. Circulation. 2014;130:1037-43.

23. Shroff GR, Skeans M, Herzog CA. Outcomes of renal transplant and waiting list patients with bacterial endocarditis in the United States. Nephrol Dial Transplant. 2008;23:2381-5.

24. Boleij A, Muytjens CMJ, Bukhari SI, Cayet N, Glaser P, Hermans PWM, et al. Novel clues on the specific association of Streptococcus gallolyticus subsp. gallolyticus with colorectal cancer. J Infect Dis. 2011;203:1101-9.

25. Park IJ, You YN, Agarwal A, Skibber JM, Rodriguez-Bigas MA, Eng $\mathrm{C}$, et al. Neoadjuvant treatment response as an early response indicator for patients with rectal cancer. J Clin Oncol. 2012;30:1770-6.

26. Danne C, Entenza JM, Mallet A, Briandet R, Débarbouillé M, Nato F, et al. Molecular characterization of a Streptococcus gallolyticus genomic island encoding a pilus involved in endocarditis. J Infect Dis. 2011;204:1960-70.

27. Greenland S, Pearl J, Robins JM. Causal diagrams for epidemiologic research. Epidemiology. 1999;10:37-48. 